\title{
Primary tubal carcinoma with a preoperative diagnosis of tubo-ovarian abscess: a case report
}

\author{
Murat Bozkurt, ${ }^{1}$ Duygu Kara, ${ }^{2}$ Y. Tahsin Ayanoglu ${ }^{3}$
}

Key words: Primary tubal carcinoma, preoperative diagnosis, tuboovarian abscess

\begin{abstract}
Primary tubal carcinoma is a rare carcinoma type that is quite difficult to diagnose preoperatively. In this case report, a patient who was operated by reason of preliminary diagnosis of tuboovarian abscess in our clinic was diagnosed with primary tubal adenocarcinoma histopathologically. The patient was designated as stage lic, and she received chemotherapy and radiotherapy. She developed recurrence after a remission period, and her illness aggrevated into stage IV. After 36 months from diagnosis, the patient died due to respiratory failure.
\end{abstract}

${ }^{1}$ Department of Obstetrics and Gynecology, Universal Hospitals Group, Malatya, Turkey

${ }^{2}$ Department of Radiology, Yeditepe University Hospital, İstanbul, Turkey

${ }^{3}$ Department of Obstetrics and Gynecology, Taksim Education and Research Hospital, İstanbul, Turkey

\section{INTRODUCTION}

Primary tubal carcinomas represent 0.15 $\%-1.8 \%$ of all female genital system carcinomas and are extremely rare, ${ }^{1}$ with an incidence of $3.61,000,000 .^{2}$ It was first reported in 1847, and 1600 cases have been reported through 2000 with 20-30 new cases reported annually. ${ }^{3}$ The average age at diagnosis is between 5560 years old with $6 \%$ of cases younger than 40 years old. ${ }^{4}$ Clinical presentation, staging and treatment approaches are identical to those used for ovarian carcinomas. Indeed, both carcinomas have some common features: similar age spectrum, frequent occurence in nulliparous females, predominantly serous papillary histology, correlation between stage and prognosis, correlation between residual tumor volume and survival,and good responses to platinumbased chemotherapy during the initial period. $^{5}$ We present a case that was postoperatively diagnosed as primary tubal carcinoma in our clinic and discuss this case in comparison with others reported in the literature.

\section{CASE PRESENTATION}

A 57-year-old woman presented at the Taksim Education and Research Hospital, Gynecology and Obstetrics Department on $12 / 24 / 2002$, with prolapsed uterus and pollakiuria. Her complaint started 5-6 months prior to presentation. She has been in menopause for six years with a previous history as follows: pregnancy 2 , parity 2 , abortus 0 , curettage 0 . She had a history of pelvic inflammatory disease and compensated diabetes mellitus (Type II). Vaginal examination showed 2 degree prolapse both on anterior-posterior wall of vagina with effort. There was an atrophic column with invisible fornices. The 9-10 week-size uterus was anteverted. A myoma 5-6 cm in diameter was detected in the posterior wall. Both adnexal regions were sensitive. Transvaginal ultrasonography (TVUSG) showed larger uterus sizes, anteversion and anteflexion

Please cite this paper as: Bozkurt M, Kara D, Ayanoglu YT. Primary tubal carcinoma with a preoperative diagnosis of tubo-ovarian abscess: a case report. Proc Obstet Gynecol. 2012;2(4):Article 6 [ 7 p.]. Available from: http://ir.uiowa.edu/pog/. Free full text article.

Corresponding author: Murat Bozkurt, Department of Obstetrics and Gynecology, Universal Malatya Hastanesi Turgut Özal Bulvarı Ankara Asfaltı 6 km No:219 44000 MALATYA /TURKEY Telephone: 904222382828/1546; Fax: 904222382600, jindrmb@yahoo.com. 
of the uterus, and an intramuralsubserous myoma in the posterior wall with a $52 \times 53 \mathrm{~mm}$ diameter. Left ovary was normal in size. The right adnexal region contained areas of hypo- and hyperechogen $4 \times 5 \mathrm{~cm}$ in diameter. Cervicovaginal smear obtained one week before the operation was reported as inflammatory smear. The patient was preoperatively diagnosed with a tuboovarian abscess with abdominal pain, tenderness and an eleveated fever with leukocytes and underwent urgent laparotomy. In exploration, a myoma in the posterior wall of the uterus $5-6 \mathrm{~cm}$ in diameter was discovered. Both ovaries were normal. Right tube showed hydrosalpinx 5-6 cm in diameter. There was little fluid in abdomen; fluid was assessed as reactive and aspirated for postoperative pathologic observation. Total abdominal hysterectomy+bilateral salpingo-oophorectomy (TAH+BSO) +colporrhaphy anterior+ colporrhaphy posterior was performed. She received a blood transfusion (1 unit) postoperatively and no complications during follow-up. Her sutures were removed and she was discharged on the sixth day. After pathologic diagnosis, CA- 125 was 375.5 $\mathrm{U} / \mathrm{ml}$. The oncology department continued follow-up and planned systemic chemotheraphy with five rounds of cisplatin $60 \mathrm{mg} / \mathrm{m} 2$ and cyclophosphamide $600 \mathrm{mg} / \mathrm{m} 2$. The patient did not tolerate chemotheraphy and only four rounds were adminstered. In accordance with the opinion of the Council of Oncology, the patient underwent complete irradiation with cobalt or photon energies of $23 \mathrm{MV}$ (administering a daily dose of 2 Gy resulted in a total of 45-52 Gy in the pelvic areas) for palliative purpose. After these treatments, CA- 125 decreased to $14 \mathrm{U} / \mathrm{ml}$. The patient presented in the oncology clinic on 9/21/2004 with abdominal pain, abdominal distension and difficulty with defecation. A $10 \times 12 \mathrm{~cm}$ pelvic mass and diffuse ascites were apparent by computerized tomography
(CT) and ultrasonography (USG). The CA-125 was $111.7 \mathrm{U} / \mathrm{ml}$. Paracentesis was performed and the patient denied survical intervention, therefore preventing restaging. She received radiotheraphy and, after one month, six rounds of systemic chemotheraphy with taxol and carboplatin was administered. On $9 / 2 / 2005$, she was scanned by magnetic resonance imaging because of increased tumor markers and irregular vaginal cuff. Multiple lymphadenopathies, the largest of which was $3 \times 2 \mathrm{~cm}$ in size, were viewed in both inguinal regions. There was diffuse edema in the inguinal region. Thorax CT showed a few pretracheal lymph nodes $5 \mathrm{~mm}$ in diameter. Nodules approximately $5 \mathrm{~mm}$ in diameter were detected in the left lung superior lobe anterior side and in the inferior lobe superior segment. The case was assessed as stage 4. Chemotheraphy was planned but the patient refused treatment.

\section{DISCUSSION}

According to previously published reports, the average age for primary tubal carcinoma is between 55-60 years of age. Low parity number, late menopause time, chronic salpingitis, and infertility are frequently associated with carcinoma. ${ }^{6}$ Our case was multipara and she did not have a history of late menopause time. Her most important risk factor was the history of pelvic inflammatory disease. In their study of 11 cases, Benjamin et al. estimated the average parity as 2.5 and reported that there is a lower association between tubal carcinoma and parity in comparison to the association with endometrial and ovarian carcinoma. In addition, they reported hypertension, diabetes mellitus and cerebrovascular events in their group. These diseases are frequent in aged populations, leading the authors to suggest that these diseases are not risk factors themselves but rather an age-associated factor. ${ }^{7}$ Our case had 
compensated DM-2. The most frequent symptoms of tubal carcinoma are abdominal pain, vaginal discharge and bleeding. The pain is colic, and it can be continuous or knife-like. The reason for colic pain is increased peristaltism and lumen distension, which causes the pain to be continuous and disguising the origins. $^{8}$ Latzko named the triad as "tubae profluence" that is formed with large watery vaginal discharge, colic pain in lower abdomen and adnexal mass. These characteristics are pathognomonic for tubal carcinoma. Today, this triad occurs in $3-14 \%$ of cases, a low ratio. ${ }^{9}$ Our case had inguinal pain in the absence of vaginal bleeding and discharge. In the literature, there are some cases that, while investigating for the etiology of ascites, tubal carcinoma was detected. ${ }^{10}$ In advanced cases ascites can be found. Our case did not have ascites in the preoperative period. It is very difficult to diagnose a tubal carcinoma preoperatively. Our patient with a preoperative diagnosis of a tubo-ovarian abscess with abdominal pain, tenderness and an eleveated fever with leukocytes underwent urgent laparotomy. McGoldrich has reported that only one of 376 cases was diagnosed in preoperative period. ${ }^{11}$ Eddy has reported 2 of 74 patients and Podratz has reported 3 of 47 patients were diagnosed preoperatively in their studies. $^{12,13}$ In Turkey, Ayhan and et al. have reported that no diagnoses were made preoperatively in their study of eight cases. ${ }^{14}$ Two cases, which were operated because of Saundra Meigs syndrome and acute hemoperitoneum, were diagnosed with frozen sections. ${ }^{15}$ Atypic masses which are suspected and originated from the fallopian tube can be frozen and this can help with diagnosis. Our case was not diagnosed preoperatively. Tubal adenocarcinoma on the right side was assessed preoperatively as a tubaovarian abscess, and during the operation as hydrosalpinx. In addition, there was an inflammatory and purulent reaction in the tube that was adherent to the posterior uterus, with no abnormalities in the digestive tract identified. Analysis of frozen sections was not performed because this diagnosis was not considered. Due to its rarity, preoperative diagnosis of primary fallopian tube carcinoma is rarely made. It is usually misdiagnosed as ovarian carcinoma, tubo-ovarian abscess or ectopic pregnancy. Primary tubal carcinoma can appear as acute pelvic peritonitis. ${ }^{16}$ Transvaginal ultrasonography provides important information to assess fallopian tube wall structure, luminal substance and the relations with pelvic structures. Kurjak et al. initially diagnosed stage 1 tubal carcinoma using colored and pulsed doppler USG.$^{17}$ A 60 year old woman was assessed with doppler USG; in papillary projections and solid areas of the mass resistance index (RI) was 0.39 and pulsative index (PI) was 0.45 . According to Doppler criteria, tubal carcinoma was the suspected diagnosis and pathology confirmed this diagnosis. ${ }^{18}$ Podobnik et al. described a 69 year old patient with right low quadrant pain and excessive watery vaginal discharge. They performed USG and identified a $6 \times 2 \times 2.5$ $\mathrm{cm}$ complex mass next to the right ovary with an $\mathrm{Rl}: 0.34$ and $\mathrm{Pl}: 0.62$. Vascularization of other ovary was normal. During USG, diameter and substance of the mass changed and passage of the fluid to cavitas uteri was viewed. On the strength of these findings, diagnosis of tubal carcinoma was considered and histological diagnosis was reported as clear cell carcinoma of tuba. ${ }^{19}$ Kurjak, et al. diagnosed eight tubal carcinomas preoperatively. All of these different types of carcinomas showed low vascular flow and complex masses were defined. RI was between 0.29 and 0.40 . They suggested in their articles that transvaginal colored Doppler was more reliable than other expensive methods. ${ }^{17}$ We did not perform Doppler on our case, but Doppler USG assessment of clinically 
complex masses can make contributions for a suspected diagnosis. CA 125 levels can also help in diagnosis, with increased levels in advanced stage cases. Authors are unanimous that it is more beneficial for follow up of remission and recurrence. $^{20,21}$ In our case CA 125 levels, which decreased after chemotheraphy, increased when recurrence occured. Also, decreased CA 125 levels after chemotheraphy showed that response for treatment was successful. Diagnosis is usually with histopathologic observation. In 1950, Hu et al. suggested criteria to differantiate tubal and uterine carcinomas from other malignancies. This criteria was modified by Sedlis in 1978. Macroscopically the tube appears swollen. To diffentiate from hydrosalpinx and tuboovarian abscess is possible with uncovering of specimen. Lumen is generally full with papillary or solid necrotic tumours and it is dilated. $^{22,23}$

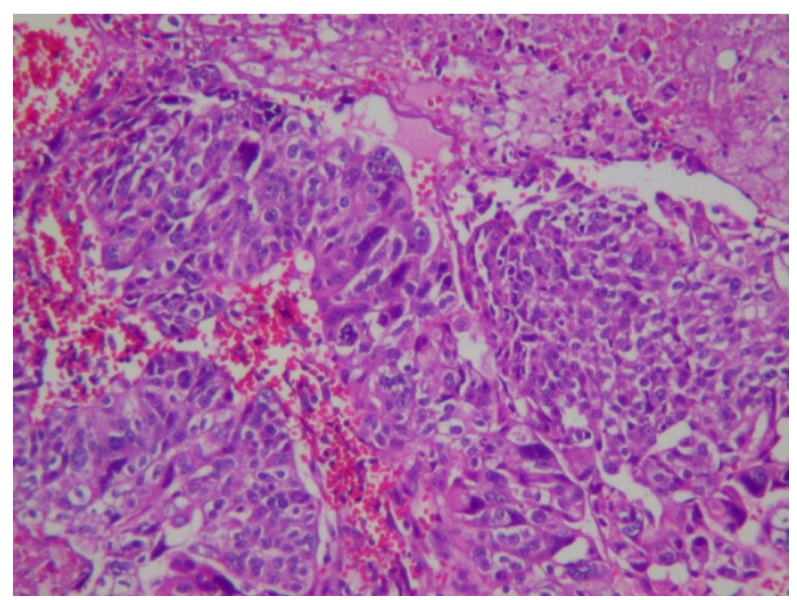

Figure 1: Adenocarcinoma areas that contain small nucleoli, big, oval-circular, vesicular nuclei, some of them with bizarre nucleus, and columnar-cuboid cells with eosinophilic cytoplasm.

In our case the tube showed a cystic appearance with a diamerter of $4 \mathrm{~cm}$ in its largest region. Cross-sectionly there was tumor proliferation in a papillary and solid style in lumen. Microscopic observation of this macroscopically-defined lesion showed tumor proliferation, some necrosis, solid development in papillaries and wall, small nucleolus, large, oval circular, vesicular nucleus, some of them with bizarre nucleus, and columnarcuboid cells with eosinophilic cytoplasm.

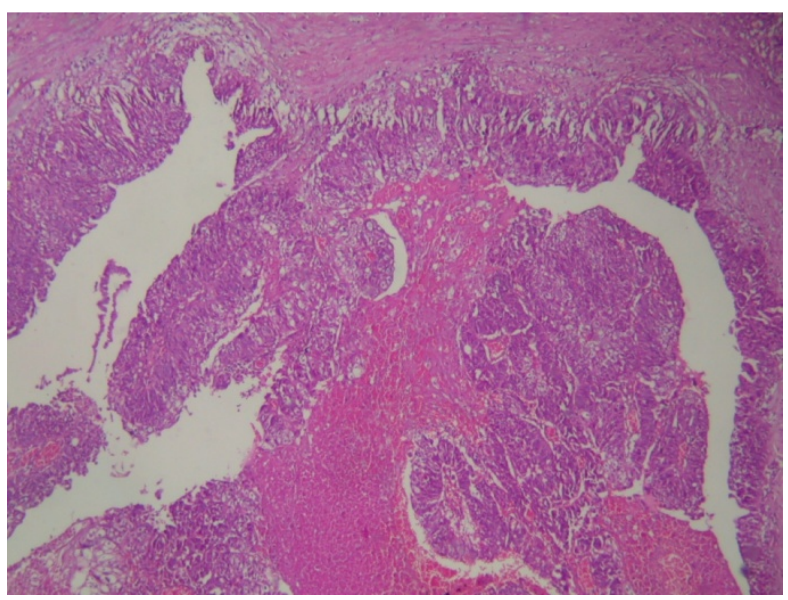

Figure 2: Adenocarcinoma areas that contain small nucleoli, big, oval-circular, vesicular nuclei, some of them with bizarre nucleus, and columnar-cuboid cells with eosinophilic cytoplasm.

There were tumor invasions into the cervix, myometrium, in both ovaries and in the opposite tube inside the lymphatics. There were malignant epithelial tumor cells in the abdominal elution fluid. The case was diagnosed as middle degree differentiated serous papillary adenocarcinoma. According to FIGO classification system, our case was assessed as in stage II c because there were ovary and/or uterus invasions and tumor cells in ascites and peritoneal washings.

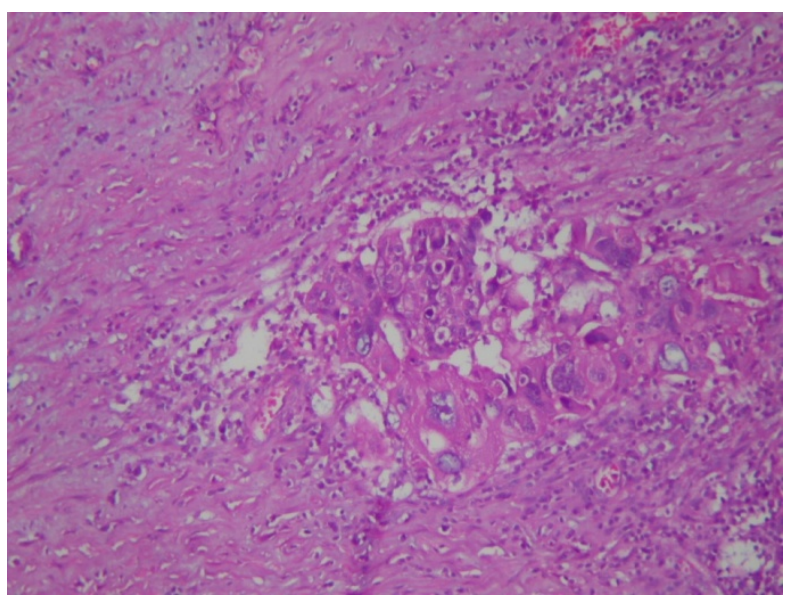

Figure 3: Adenocarcinoma areas that contain small nucleoli, big, oval-circular, vesicular nuclei, some of them with bizarre nucleus, and columnar-cuboid cells with eosinophilic cytoplasm. 
The use of pap smear for diagnosis of primary tubal carcinoma is controversial. There are different results for pap smears in the literature, some of them are associated with a very optimistic, with a $>\% 25$, positive result. ${ }^{24}$ If psammoma bodies are viewed in the cervicovaginal smear and the age of the patient is suitable, the possibility of tubal carcinoma should be considered. ${ }^{25}$ The treatment approach for primary tubal carcinoma is similar to the approach for ovary carcinoma. Basic treatment is bilateral salpingo-oophorectomy and abdominal hysterectomy. However, if staging is desired, the following should be performed during surgery: peritoneal washings, ascites sampling if present, biopsies from surface of diaphagm, infracolic omentectomy, and retroperitoneal lymph node sampling. ${ }^{26}$ Cytoreductive surgery in stage 3 and stage 4 patients provides significiant contribution for prognosis. $^{27}$ Postoperative chemotheraphy is currently intravenous taxol and cisplatin combination as it is used with ovary carcinomas. $^{28}$ In a phase II study of 24 patients with advanced stage tubal adenocarcinoma (Stage 3:14, Stage 4:10), patients received cyclophosphamide, adriamycin, cisplatin combination; 10 patients demonstrated a complete response and 6 patients a partial response (response ratio:95\%, confidence interval (45\%-84\%)). Response ratios are assessed as moderate, and adverse effects are acceptable. ${ }^{29} \mathrm{TAH}+\mathrm{BSO}$ was performed. The patient had a partial response to postoperative chemotheraphy and second line chemotheraphy was performed for subsequent recurrence. Despite the size of the mass becoming smaller, it was not a satisfactory response. Postoperative radiotherapy is not recommended because efficiency is low and serious complications are common. $^{30}$ We used radiotheraphy for palliative purposes in our case and there were not any complications. Initially radiotherapy is performed frequently but this therapy cannot prevent spreading to the upper abdomen. ${ }^{31}$ In our case radiotherapy could not control the disease, so it spread to the upper abdomen. In cases with tubal carcinoma, 5 -year survival is between $30-50 \%$, regardless of stage. ${ }^{32}$ The most important factor that affects the survival is the stage of the disease at the time of diagnosis. Benedet and Miller have estimated 5-year survival in their metaanalyse which contains 6 studies with a total of 278 patients: Stage 1: $62 \%$, Stage 2: $36 \%$, Stage 3: $17 \%$, Stage 4: $0 \%{ }^{8}$ Rosen et al. have estimated 5 -year survival in their retrospective analyses with 115 patients: Stage 3 and $4: 13.6 \%$; Stage 1 and 2: $50.8 \%$. It is reported that to leave $>2 \mathrm{~cm}$ tumor tissue after debulking significantly worsens the prognosis. ${ }^{33}$ Our case died 36 months after diagnosis from respiratory failure.

\section{CONCLUSION}

Carcinoma of the fallopian tube should be considered in the differential diagnosis of the tubo-ovarian abscess in those who present with abdominal pain, pelvic tenderness and an eleveated fever with leukocytes.

\section{References}

1. Ajithkumar TV, Minimole AL, John MM, Ashokkumar OS. Primary fallopian tube carcinoma. Obstet Gynecol Surv. 2005 Apr;60(4):247-52. PubMed PMID: 15795632.

http://dx.doi.org/10.1097/01.ogx.0000158 506.23663.79

2. Rosenblatt KA, Weiss NS, Schwartz SM. Incidence of malignant fallopian tube tumors. Gynecol Oncol. 1989 Nov;35(2):236-9. PubMed PMID: 2807017. http://dx.doi.org/10.1016/00908258(89)90051-6

3. Azodi M, Langer A, Jenison EL. Primary fallopian tube carcinoma with isolated 
torsion of involved tube. Eur $\mathrm{J}$ Gynaecol Oncol. 2000;21(4):364-7. PubMed PMID: 11055483.

4. Alvarado-Cabrero I, Young $\mathrm{RH}$, Vamvakas EC, Scully RE. Carcinoma of the fallopian tube: a clinicopathological study of 105 cases with observations on staging and prognostic factors. Gynecol Oncol. 1999 Mar;72(3):367-79. PubMed PMID: 10053109. http://dx.doi.org/10.1006/gyno.1998.5267

5. Schneider C, Wight E, Perucchini D, Haller U, Fink D. Primary carcinoma of the fallopian tube. A report of 19 cases with literature review. Eur J Gynaecol Oncol. 2000;21(6):578-82. Review. PubMed PMID: 11214613.

6. Jereczek B, Jassem J, Kobierska A. Primary cancer of the fallopian tube. Report of 26 patients. Acta Obstet Gynecol Scand. 1996 Mar;75(3):281-6. PubMed PMID: 8607344. http://dx.doi.org/10.3109/0001634960904 7102

7. Piura B, Rabinovich A. Primary carcinoma of the fallopian tube: study of 11 cases. Eur J Obstet Gynecol Reprod Biol. 2000 Aug;91(2):169-75. PubMed PMID: 10869791.

http://dx.doi.org/10.1016/S0301-

\section{5(99)00264-X}

8. Benedet JL, Miller DM. Tumors of fallopian tube: clinical features, staging and management. In: Coppleson $\mathrm{M}$, Monaghan JM, Morrow CP, Tattersall MHN, editors. Gynecologic oncology: fundamental principles and clinical practice. New York: Churchill Livingstone 1992; p.853- 60.

9. McMurray EH, Jacobs AJ, Perez CA, Camel HM, Kao MS, Galakatos A. Carcinoma of the fallopian tube. Management and sites of failure. Cancer. 1986 Nov 1;58(9):2070-5. PubMed PMID: 3756822. http://dx.doi.org/10.1002/10970142(19861101)58:9<2070::AIDCNCR2820580918>3.0.CO;2-3

10. Akyol A, Yumru A.E, Baksu B, Davas I, Kara A. Primer ve Metastatik Tuba Karsinomu: İki Olgu Sunumu. Jinekoloji ve Obstetrik Dergisi 2001; 15: 41- 44.

11. McGoldrick JL, Strauss H, Rao J. Primary carcinoma of the fallopian tube. Am J
Surg 1943; 59: 559-63.

http://dx.doi.org/10.1016/S00029610(43)90542-2

12. Eddy GL, Copeland LJ, Gershenson DM, Atkinson EN, Wharton JT, Rutledge FN. Fallopian tube carcinoma. Obstet Gynecol. 1984 Oct;64(4):546-52. PubMed PMID: 6541328.

13. Podratz KC, Podczaski ES, Gaffey TA, O'Brien PC, Schray MF, Malkasian GD Jr. Primary carcinoma of the fallopian tube. Am J Obstet Gynecol. 1986 Jun;154(6):1319-26. PubMed PMID: 3013008.

14. Ayhan A, Deren O, Yuce K, Tuncer Z, Mocan G. Primary carcinoma of the fallopian tube: a study of 8 cases. Eur $\mathrm{J}$ Gynaecol Oncol. 1994;15(2):147-51. Review. PubMed PMID: 8005146.

15. Soundara RS, Ramdas CP, Reddi RP, Oumachigni A, Rajaram P, Reddy KS. A review of fallopian tube carcinoma over 20 years in Pondicherry. Indian $\mathrm{J}$ Cancer 1991;28:188- 95.

16. Verit FF, Kafali H. Primary carcinoma of the fallopian tube mimicking tubo-ovarian abscess. Eur J Gynaecol Oncol. 2005;26(2):225-6. PubMed PMID:15857038.

17. Kurjak A, Kupesic S, Ilijas M, Sparac V, Kosuta D. Preoperative diagnosis of primary fallopian tube carcinoma. Gynecol Oncol. 1998 Jan;68(1):29-34. PubMed PMID: 9454656. http://dx.doi.org/10.1006/gyno.1997.4873

18. Kurjak A, Bonilla- Musoles F, Kupesic S. The diagnosis of benign and malignant tumors of the fallopian tube, in TimorTritsch IE, Kurjak A, editors. Ultrasound and the fallopian tube. New York: Parthenon Publishers; 1995, p.85-95.

19. Podobnik M, Singer Z, Ciglar S, Bulic M. Preoperative diagnosis of primary fallopian tube carcinoma by transvaginal ultrasound, cytological finding and CA125. Ultrasound Med Biol. 1993;19(7):587-91. PubMed PMID: 8310554. http://dx.doi.org/10.1016/03015629(93)90082-Y

20. Baekelandt $M$, Jorunn Nesbakken $A$, Kristensen GB, Tropé CG, Abeler VM. Carcinoma of the fallopian tube. Cancer. 2000 Nov 15;89(10):2076-84. PubMed 
PMID:

11066048.

http://dx.doi.org/10.1002/1097-

0142(20001115)89:10<2076::AID-

CNCR7>3.0.CO;2-V

21. Ben-Ami I, Halperin R, Herman A, Schneider D. [Early stage fallopian tube carcinoma--diagnosis, staging and treatment]. Harefuah. 2004 Nov;143(11):790-3, 839. Hebrew. PubMed PMID: 15603266.

22. Alvarado-Cabrero I, Young $\mathrm{RH}$, Vamvakas EC, Scully RE. Carcinoma of the fallopian tube: a clinicopathological study of 105 cases with observations on staging and prognostic factors. Gynecol Oncol. 1999 Mar;72(3):367-79. PubMed PMID: 10053109. http://dx.doi.org/10.1006/gyno.1998.5267

23. Wheeler J.E. Diseases of the fallopian tube. In Kurman RJ, editor. Blaustein's pathology of the female genital tract, $5^{\text {th }}$ ed. New York : Springer; 2002; p. 637641.

24. Perez CA, Grigsby PW, Mutch DG, Clifford Chao KS, Basil J. Gynecologic tumors In: Rubin $\mathrm{P}$, editor. Clinical oncology: a multidisciplinary approach for physicians and students. $8^{\text {th }}$ ed. Philadelphia : W.B.Saunders; 2001: p. 462- 521.

25. Parkash V, Chacho MS. Psammoma bodies in cervicovaginal smears: incidence and significance. Diagn Cytopathol. 2002 Feb;26(2):81-6. Review. PubMed PMID: 11813323. http://dx.doi.org/10.1002/dc. 10058

26. Daskalakis G, Kiosses E, Katsetos C, Petrogiannis N, Michalas S. Primary carcinoma of the fallopian tube. Eur $\mathrm{J}$ Gynaecol Oncol. 1998;19(4):384-5. PubMed PMID: 9744731.

27. Takeshima N, Hasumi K. Treatment of fallopian tube cancer. Review of the literature. Arch Gynecol Obstet. 2000 Jul;264(1):13-9. Review. PubMed PMID: 10985612.

http://dx.doi.org/10.1007/PL00007475

28. Gemignani ML, Hensley ML, Cohen R, Venkatraman E, Saigo PE, Barakat RR. Paclitaxel-based chemotherapy in carcinoma of the fallopian tube. Gynecol
Oncol. 2001 Jan;80(1):16-20. PubMed

PMID:

11136563.

http://dx.doi.org/10.1006/gyno.2000.6012

29. Wagenaar HC, Pecorelli S, Vergote I, Curran D, Wagener DJ, Kobierska A, Bolis G, Bokkel-Huinink WT, Lacave AJ, Madronal $C$, Forn $M$, de Oliveira $C F$, Mangioni C, Nooij MA, Goupil A, Kerbrat $\mathrm{P}$, Marth $\mathrm{CH}$, Tumolo $\mathrm{S}$, Herben MG, Zanaboni F, Vermorken JB. Phase II study of a combination of cyclophosphamide, adriamycin and cisplatin in advanced fallopian tube carcinoma. An EORTC gynecological cancer group study. European Organization for Research and Treatment of Cancer. Eur J Gynaecol Oncol. 2001;22(3):187-93. PubMed PMID: 11501769.

30. Klein M, Rosen A, Lahousen M, Graf AH, Rainer $A$. The relevance of adjuvant therapy in primary carcinoma of the fallopian tube, stages I and II: irradiation vs. chemotherapy. Int J Radiat Oncol Biol Phys. 2000 Dec 1;48(5):1427-31. PubMed PMID: 11121643. http://dx.doi.org/10.1016/S03603016(00)01381-X

31. Williams S, Blessing JA, Liao SY, Ball $H$, Hanjani P. Adjuvant therapy of ovarian germ cell tumors with cisplatin, etoposide, and bleomycin: a trial of the Gynecologic Oncology Group. J Clin Oncol. 1994 Apr;12(4):701-6. PubMed PMID: 7512129.

32. Rauthe G, Vahrson HW, Burkhardt E. Primary cancer of the fallopian tube. Treatment and results of 37 cases. Eur $\mathrm{J}$ Gynaecol Oncol. 1998;19(4):356-62. PubMed PMID: 9744726.

33. Rosen A, Klein M, Lahousen M, Graf $A H$, Rainer A, Vavra N. Primary carcinoma of the fallopian tube--a retrospective analysis of 115 patients. Austrian Cooperative Study Group for Fallopian Tube Carcinoma. Br J Cancer. 1993 Sep;68(3):605-9. PubMed PMID: 8353051; PubMed Central PMCID: PMC1968398.

http://dx.doi.org/10.1038/bjc.1993.394 